\title{
Molecular genetic analysis of the region containing the essential Pseudomonas aeruginosa asd gene encoding aspartate- $\beta$ - semialdehyde dehydrogenase
}

\author{
Tung T. Hoang, ${ }^{1,2}$ Scott Williams, ${ }^{2}$ Herbert P. Schweizer ${ }^{1,3}$ \\ and Joseph S. Lam ${ }^{3,4}$ \\ Author for correspondence: Herbert P. Schweizer. Tel: +1970 491 3536. Fax: +1970 4911815 \\ e-mail: hschweizer@vines.colostate.edu
}

1 Department of Microbiology, Colorado

State University, Fort

Collins, CO 80523, USA

2 Department of Microbiology \& Infectious

Diseases, University of Calgary Health Sciences Center, Calgary, Alberta, Canada T2N 4N1

3,4 Canadian Bacterial Diseases Network ${ }^{3}$ and Department of Microbiology 4 , University of Guelph, Guelph, Ontario, Canada N1G 2W1 asd mutants of Gram-negative and some Gram-positive bacteria have an obligate requirement for diaminopimelic acid (DAP), an essential constituent of the cell wall of these organisms. In environments deprived of DAP, for example mammalian tissues, they will undergo lysis. This was previously exploited to develop vaccine strains of Salmonella typhimurium and cloning vectors containing asd as an in vivo selectable marker. As a first step for development of such systems for Pseudomonas aeruginosa, the asd gene from wild-type strain PAO1 was cloned by a combined approach of PCR amplification from chromosomal DNA, construction of mini-libraries and by complementation of an Escherichia coli $\Delta$ asd mutant. The nucleotide sequence of a 2433 bp Smal-Nsil fragment was determined. This fragment contained the C-terminal 47 nucleotides of leuB, encoding 3-isopropylmalate dehydrogenase; asd, encoding aspartate- $\beta$-semialdehyde dehydrogenase (Asd); and orfA, whose product showed similarity to the Asd proteins from Vibrio spp. By subcloning, asd was localized to a 1.24 kb DNA fragment which in an E. coli $T 7$ expression system strongly expressed a 40000 Da protein. The amino acid sequence was deduced from the DNA sequence. A comparison of the Asd proteins from $P$. aeruginosa, $E$. coli and Haemophilus influenzae revealed greater than $63 \%$ identity, demonstrating the conserved nature of Asd in Gram-negative bacteria, and defined the active-site-containing consensus sequence GGNCTVXMLMXXXLGLF as a possible signature motif. Chromosomal $\Delta$ asd mutants were isolated. They were auxotrophic for DAP, lysine, methionine and threonine, and lysed in the absence of DAP. Genetic analyses indicated that orfA probably is naturally frame-shifted and does not contribute to the Asd phenotype. By PFGE, the asd gene was mapped to between coordinates 1.89 and 2.15 Mbp, or 37-40 min, on the 5.9 Mbp P. aeruginosa chromosome.

Keywords: Pseudomonas aeruginosa, asd, chromosomal mapping, selectable marker, active site

\section{INTRODUCTION}

Pseudomonas aeruginosa is an opportunistic pathogen causing fatal infections in debilitated and immuno-

Abbreviations: Asd, aspartate- $\beta$-semialdehyde dehydrogenase; DAP, diaminopimelic acid.

The GenBank accession number for the sequence reported in this paper is U11055. compromised patients, especially those with granulocytopenia, severe burns and cystic fibrosis (CF) (Bodey et al., 1983). The success of this organism as a pathogen can largely be attributed to a number of virulence factors, including alginate (Govan, 1988), exotoxin A (Vasil, 1986), phospholipase C (Vasil et al., 1991), various proteases (Holder \& Neely, 1991) and lipopolysaccharide (Cryz et al., 1984). The great variety of distinct mechanisms by which these factors act and 


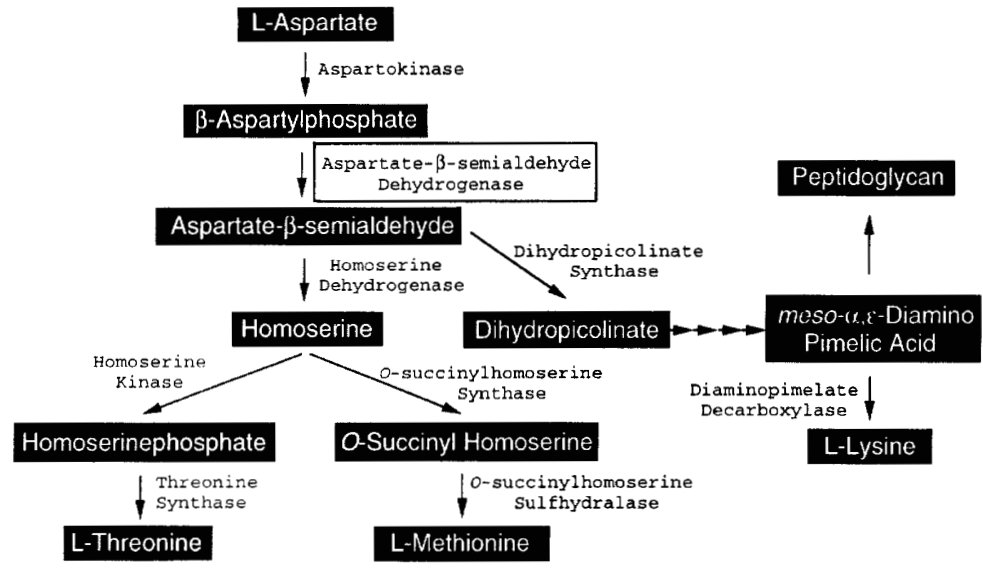

Fig. 1. The role of asd in the proposed amino acid biosynthetic pathways of DAP, lysine, methionine and threonine, and in peptidoglycan synthesis.

interact to provide a survival strategy for the bacterium has been examined in several studies (for a review, see Hoiby et al., 1989).

The asd gene encodes aspartate- $\beta$-semialdehyde dehydrogenase (Asd; EC 1.2.1.11), a key enzyme in the biosynthetic pathways for diaminopimelic acid (DAP), lysine, methionine and threonine (Fig. 1). DAP is an essential component of the peptidoglycan of all Gramnegative and some Gram-positive bacteria (Schleifer \& Kandler, 1972). In the absence of DAP, asd mutants undergo lysis. Since DAP is absent from mammalian tissues, asd mutants of Salmonella typhimurium have been exploited to construct a balanced-lethal system for vaccine delivery vehicles using a cloned asd gene as the selective marker in place of antibiotic resistance markers which are impractical in vivo (Nakayama et al., 1988). Few studies have dealt with the molecular characterization of $P$ seudomonas aeruginosa genes involved in the threonine (Clepet et al., 1992), methionine (Foglino et al., 1995) and lysine (Martin et al., 1986) amino acid biosynthetic pathways. The structural genes for homoserine dehydrogenase (hom), homoserine kinase $(t h r B)$ and threonine synthase $(t h r C)$ have been cloned, sequenced and mapped to the $10 \mathrm{~min}(t h r B)$ and $31 \mathrm{~min}$ (hom and $t h r C$ ) regions of the $P$. aeruginosa chromosome (Clepet et al., 1992). Subsequently, Foglino et al. (1995) showed that a direct sulfhydrylation pathway is used for methionine biosynthesis from homoserine. The first step is catalysed by an $\mathrm{O}$-succinylhomoserine synthase encoded by met $\dot{A}$, which is located at $20 \mathrm{~min}$ on the chromosome, and the second step is catalysed by a O-succinylhomoserine sulfhydralase encoded by $m e t Z$, which was mapped to the 40 min region of the chromosome. The structural gene for DAP decarboxylase, lys $A$, has also been cloned; its regulation was determined to be similar to that of Escherichia coli lys A (Martin et al., 1986) and it was subsequently localized to the $10 \mathrm{~min}$ region of the chromosome (Holloway et al., 1994). Despite previous trials (Clepet et al., 1992), the genes encoding the enzymes catalysing the initial steps in aspartate- $\beta$-semialdehyde synthesis, ask (aspartokinase) and asd (Asd) have hitherto remained unidentified.
The aims of the present study were to clone and characterize the asd gene from $P$. aeruginosa in order (i) to understand the role of the gene and its product in amino acid biosynthesis in this bacterium and (ii) to allow construction of a $\Delta a s d$ laboratory strain to facilitate development of genetic tools for P. aeruginosa utilizing the asd gene as an in vivo selectable marker.

\section{METHODS}

Bacterial strains and plasmids. The E. coli and $P$. aeruginosa strains used in this study are listed in Table 1. The plasmids utilized in this study were constructed as detailed in Table 1. The details underlying construction of pPS412 (Fig. 2) were as follows. A $\sim 300$ bp EcoRI biotinylated fragment from pPS410 was used to identify a $\sim 4.5 \mathrm{~kb}$ chromosomal BamHI-EcoRI fragment by genomic Southern analysis. For cloning of this DNA fragment, BamHI +EcoRI-digested PAO1 chromosomal DNA was electrophoresed on a $1 \%$ low-gelling-point agarose gel in $0.5 \times$ TBE (Sambrook et al., 1989) and the fragments from the $3-5 \mathrm{~kb}$ region of the gel were eluted as described by Wieslander (1979). After ligation into $B a m \mathrm{HI}+$ EcoRI-digested pUC18, ampicillin-resistant $\left(\mathrm{Ap}^{\mathrm{r}}\right)$ $\mathrm{DH} 5 \alpha \mathrm{F}^{\prime}$ colonies were selected and pooled. Plasmid DNA was isolated (Xiang et al., 1994) and used to transform $\triangle a s d$ E. coli strain SH309 to Ap resistance on LB medium without DAP supplementation. All putative $\mathrm{Asd}^{+}$transformants contained the cloned $4.5 \mathrm{~kb} \mathrm{BamHI-EcoRI} \mathrm{fragment.}$

Growth media. LB medium (Miller, 1992) was routinely used as the rich medium for all bacterial strains. The minimal media employed were M9 (Miller, 1992) for E. coli and M9 or VBMM (Schweizer, 1991) for P. aeruginosa. For growth of asd mutants, the media were supplemented with $100 \mu \mathrm{g} \mathrm{DAP} \mathrm{ml^{-1 }}$

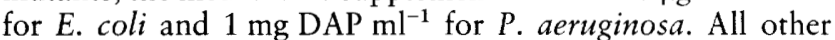
amino acids were present at $40 \mu \mathrm{g} \mathrm{ml}^{-1}$ and glucose was added to $\mathrm{M} 9$ medium as carbon source to a final concentration of $10 \mathrm{mM}$. Concentrations of antibiotics used in selection media

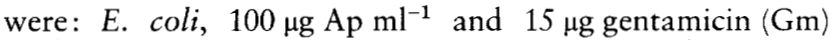
$\mathrm{ml}^{-1} ; P$. aeruginosa; $500 \mu \mathrm{g}$ carbenicillin $(\mathrm{Cb}) \mathrm{ml}^{-1}$ and $200-$ $300 \mu \mathrm{g} \mathrm{Gm} \mathrm{ml} \mathrm{m}^{-1}$.

DNA procedures. For PCR amplification of an asd fragment from chromosomal DNA, two oligonucleotides, P1 (5'-TGCCAGGGCGACTAC) and P2 (5'-[G/G][G/C][T/A][C/G]GC[C/G]GCCTGGTAGGT) were used to prime synthesis from PAO1 (Holloway \& Zhang, 1990) chromosomal DNA following previously described conditions (Kureishi \& Bryan, 1992). The $50 \mu \mathrm{lPCR}$ reaction mixture contained $1 \times \mathrm{PCR}$ 
Table 1. Bacterial strains and plasmids

\begin{tabular}{|c|c|c|}
\hline Strain or plasmid & Relevant properties & Reference/origin \\
\hline \multicolumn{3}{|l|}{ P. aeruginosa } \\
\hline PAO1 & Prototroph & Holloway \& Zhang (1990) \\
\hline PAO183 & PAO1 $\Delta($ asd-orfA $) \Omega \mathrm{Gm}^{\mathrm{r}} F R T$ & This study \\
\hline PAO184 & PAO1 $\triangle a s d:: \mathrm{Gm}^{\mathrm{r}} F R T$ & This study \\
\hline PAO185 & PAO1 1 asd: : $\Omega \mathrm{Gm}^{\mathrm{r}} F R T$ & This study \\
\hline PG201 & Prototroph & Ochsner et al. (1994) \\
\hline UO606 & PG201 glpK: :Tn5Gm & $\begin{array}{l}\text { Urs Ochsner, University of } \\
\text { Colorado Health Sciences } \\
\text { Center, CO, USA }\end{array}$ \\
\hline \multicolumn{3}{|l|}{ E. coli } \\
\hline $\mathrm{DH} 5 \alpha \mathrm{F}^{\prime}$ & $\begin{array}{l}{\left[\mathrm{F}^{+} \phi 80 l a c Z \Delta \mathrm{M} 15\right] \Delta(\operatorname{lac} Z Y A-\arg F) \mathrm{U} 169 \text { recA1 endA1 hsdR17 }\left(\mathrm{r}_{\mathrm{K}}^{-} \mathrm{m}_{\mathrm{K}}^{+}\right)} \\
\text {supE44 thi-1 gyrA relA1 }\end{array}$ & Liss (1987) \\
\hline BL21(DE3) & E. coli $\mathrm{B} \mathrm{F}^{-} \operatorname{omp} T\left(\mathrm{r}_{\mathrm{B}}^{-} \mathrm{m}_{\mathrm{B}}^{-}\right)(\lambda \mathrm{DE} 3)$ & Studier et al. $(1990)$ \\
\hline SH309 & $\begin{array}{l}\mathrm{F}^{-} \text {araD139 } \Delta(\text { argF-lac) } \mathrm{U} 169 \text { rpsL150 deoC1 ptsF25 flbB5301 rbsR } \\
\text { relA1 } \Delta(\text { mal-asd }) 3 \text { ugpA704: :Tn10 }\end{array}$ & Schweizer et al. (1986) \\
\hline \multicolumn{3}{|l|}{ Plasmids } \\
\hline $\mathrm{pAC} \Omega \mathrm{Gm}$ & $\mathrm{Gm}^{\mathrm{r}}, \mathrm{Tc}^{\mathrm{r}}$; source of $\mathrm{Gm}^{\mathrm{r}} \Omega$ fragment & Schweizer \& Hoang (1995) \\
\hline pBluescript SK- & $A p^{r} ;$ multipurpose cloning vector & Stratagene \\
\hline pCRII & $\mathrm{Ap}^{r} ;$ PCR fragment TA cloning vector & Invitrogen \\
\hline $\mathrm{pEX} 100 \mathrm{~T}$ & $\mathrm{Ap}^{\mathrm{r}} ; s a c B^{+}$ori $T^{+}$; gene replacement vector & Schweizer \& Hoang (1995) \\
\hline pFGS1 & $\begin{array}{l}\mathrm{Ap}^{\mathrm{r}}, \mathrm{Gm}^{\mathrm{r}} \text {; source of } \mathrm{Gm} \text {-resistance-conferring fragment flanked by } \\
\text { FRT sites } \dagger\end{array}$ & Laboratory collection \\
\hline pMO010323 & $\mathrm{Tc}^{\mathrm{r}}$; mobilizable cosmid vector; complements leuB and asd & Hoang \& Schweizer (1997) \\
\hline $\mathrm{pUC18} / 19$ & $\mathrm{Ap}^{\mathrm{r}} ;$ multipurpose cloning vectors & Yanisch-Perron et al. (1985) \\
\hline pUCP20/21 & $\mathrm{Ap}^{\mathrm{r}}$; broad-host-range cloning derivatives of pUC18/19 & West et al. (1994) \\
\hline pUCP20T & $\mathrm{Ap}^{\mathrm{r}}$; mobilizable derivative of $\mathrm{pUCP} 20$ & Schweizer et al. (1996) \\
\hline pPS410 & $\mathrm{Ap}^{\mathrm{r}} ;(281 \mathrm{bp}$ PCR fragment cloned into pCRII $)$ & This study \\
\hline pPS412 & $\begin{array}{l}\mathrm{Ap}^{\mathrm{r}} ; \text { asd } d^{+} \text {leu } \mathrm{B}^{+} \text {orf } \mathrm{A}^{+}(4.5 \mathrm{~kb} \text { Bam HI-EcoRI chromosomal DNA } \\
\text { fragment cloned between same sites of pUC18; all genes are in same } \\
\left.\text { direction as } \mathrm{P}_{l a c}{ }^{*}\right)\end{array}$ & This study \\
\hline pPS452 & $\begin{array}{l}\mathrm{Ap}^{\mathrm{r}} \text {; } \Delta a s d \text { (pPS412 with } 0.95 \mathrm{~kb} S m a \mathrm{l} \mathrm{Gm}{ }^{\mathrm{r}} \text { fragment from } \mathrm{pAC} \Omega \mathrm{Gm} \\
\text { between ClaI sites) }\end{array}$ & This study \\
\hline pPS454 & $\begin{array}{l}\text { Ap }^{r} ; \text { asd }^{+} \text {leu } B^{+} \text {orf } A^{+}(3 \cdot 1 \mathrm{~kb} \text { Bam HI-SphI fragment from pPS } 412 \\
\text { cloned between same sites of pUC18; all genes are in opposite } \\
\left.\text { direction as } \mathrm{P}_{l a c}\right)\end{array}$ & This study \\
\hline pPS455 & $\mathrm{Ap}^{\mathrm{r}} ;$ asd $^{+} \operatorname{orf}^{+}($SmaI deletion of pPS412) & This study \\
\hline pPS456 & $\begin{array}{l}\mathrm{Ap}^{\mathrm{r}} ; \text { asd }^{+} \text {orf } \mathrm{A}^{+}(2 \cdot 1 \mathrm{~kb} \text { BamHI-PstI fragment from pPS412 cloned } \\
\left.\text { between same sites of pUC18; both genes are in same direction as } \mathrm{P}_{\text {lac }}\right)\end{array}$ & This study \\
\hline pPS457 & $\begin{array}{l}\mathrm{Ap}^{\mathrm{r}} ; a s d^{+}[1.2 \mathrm{~kb} \text { EcoRI-ClaI (partial) fragment from pPS456 cloned } \\
\text { between same sites of pBluescript SK-] }\end{array}$ & This study \\
\hline pPS600 & $\begin{array}{l}\mathrm{Ap}^{\mathrm{r}} ; \text { asd } d^{+} \text {leuB } \mathrm{B}^{+} \text {orf } \mathrm{A}^{+}(4 \cdot 6 \mathrm{~kb} \text { EcoRI-HindIII fragment from pPS412 } \\
\text { cloned into the same sites of pUCP20T) }\end{array}$ & This study \\
\hline pPS704 & $\begin{array}{l}\mathrm{Ap}^{\mathrm{r}} ; \text { asd }^{+} \text {leuB } \mathrm{B}^{+} \text {orf } \mathrm{A}^{+}(6 \cdot 5 \mathrm{~kb} E c o \mathrm{RI} \text { fragment from pMO010323 } \\
\text { cloned into EcoRI site of pUC18) }\end{array}$ & This study \\
\hline pPS716 & $\begin{array}{l}\mathrm{Ap}^{\mathrm{r}}, \mathrm{Gm}^{\mathrm{r}} \text {; source of } \mathrm{Gm} \text {-resistance-conferring } \Omega \text { fragment flanked by } \\
\text { FRT sites } \dagger\end{array}$ & Laboratory collection \\
\hline
\end{tabular}

" $\mathrm{P}_{l a c}$, lac operon promoter.

†FRT, yeast Flp recombinase target.

buffer (Promega) (50 mM Tris $/ \mathrm{HCl}$ pH 8.0, 50\% glycerol, $100 \mathrm{mM} \mathrm{NaCl}, 0 \cdot 1 \mathrm{mM}$ EDTA, $5 \mathrm{mM}$ DTT, $1 \%$ Triton X100), $200 \mu \mathrm{M}$ of each dNTP, $1.5 \mathrm{mM} \mathrm{MgCl}_{2}, 25 \mathrm{pmol}$ of each primer, $100 \mathrm{ng}$ chromosomal DNA and $2.5 \mathrm{U}$ Taq DNA polymerase (Promega). The $\sim 280 \mathrm{bp}$ PCR fragment was eluted from a $2 \%$ agarose gel in $0.5 \times$ TBE utilizing the
SpinBind protocol (FMC Bioproducts) and ligated to the pCRII TA-cloning vector following the protocol provided by the supplier (Invitrogen). For Southern analysis, chromosomal PAO1 DNA was digested with various restriction endonucleases, electrophoresed on a $1 \%$ agarose gel in $0.5 \times \mathrm{TBE}$ (Sambrook et al., 1989) and transferred to Photogene nylon 


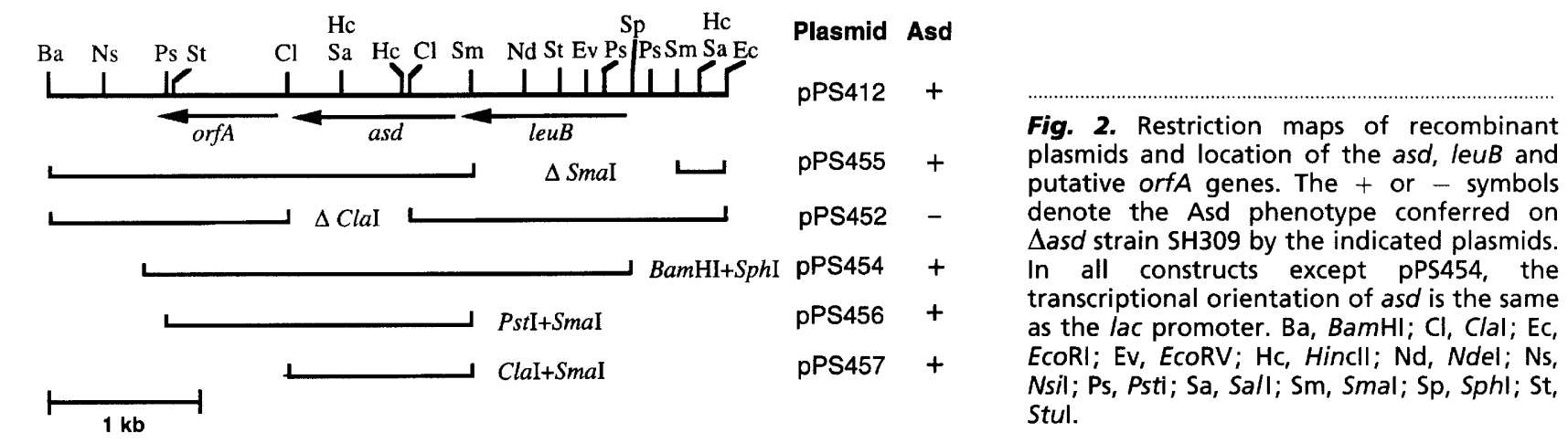

membranes (Gibco BRL) as described by Sambrook et al. (1989). Plasmid DNA was biotinylated by random hexamer priming following the NEBlot Phototype kit protocol (New England Biolabs). Following transfer and UV fixation (Sambrook et al., 1989), the membranes were probed with the biotinylated DNA fragment according to the Phototype detection kit protocol (New England Biolabs). Nucleotide sequences were determined utilizing the Taq Dye Deoxy Terminator Cycle Sequencing kit and the protocol provided by the supplier (Applied Biosystems). Extensions were primed utilizing the commercially available 24 nt pUC/M13 reverse and forward sequencing primers, respectively. Labelled samples were analysed in the University of Calgary DNA Analysis Core Facility on an Applied Biosystems Model 373A DNA sequencer. Computer-assisted sequence analyses were performed utilizing the MacDNAsis (Hitachi Software Engineering), SeqEd (Applied Biosystems) and SeqVu (Garvan Medical Institute, Sidney, Australia) programs. GenBank homology searches were performed utilizing the online BLAST facilities of the National Center for Biotechnology Information at the National Library of Medicine (Bethesda, MD, USA). PROSITE searches were performed via the ExPASy World Wide Web (WWW) molecular biology server from the Geneva University Hospital and the University of Geneva, Switzerland. PFGE electrophoresis was performed according to the previously established procedure (Lightfoot \& Lam, 1993). Other routine DNA methods were performed as previously described (Schweizer \& Po, 1994).

Expression of plasmid-encoded polypeptides. These were overexpressed and identified with the bacteriophage T7 RNA polymerase/T7 promoter system (Studier et al., 1990). Plasmids pT7-5asd and pT7-6asd were constructed by subcloning a $1.8 \mathrm{~kb}$ EcoRI-HindIII fragment harbouring asd from pPS456 (Fig. 2) into EcoRI + HindIII-cleaved pT7-5 and pT7-6 DNA (Tabor, 1994), respectively. Thus, in pT7-5asd transcription from the $\Phi 10$ promoter proceeds from the $S m a$ I site towards the ClaI sites as indicated for pPS412 in Fig. 2, and in pT7-6asd transcription from the $\Phi 10$ promoter proceeds from the SmaI site towards the ClaI sites. The host strain was BL21(DE3), which contains the gene for T7 RNA polymerase under the control of the IPTG-inducible lacUV promoter (Studier et al., 1990). The product of the cloned genes were selectively labelled with $\left[{ }^{35} \mathrm{~S}\right]$ methionine as previously described (Schweizer, 1991). Proteins were separated on a $0 \cdot 1 \%$ SDS $/ 10 \%$ polyacrylamide gel $(\mathrm{pH} 9 \cdot 2)$ (Makowski \& Ramsby, 1993). The destained gels were soaked in $1 \mathrm{M}$ sodium salicylate (Chamberlain, 1979), dried and visualized by autoradiography.

Isolation of chromosomal asd mutations. A PCR-based strategy was employed to isolate chromosomal $\Delta a s d$ mutants.
For reverse PCR amplification of fragments missing the 1111 bp asd coding region alone or lacking 2225 bp encompassing both the asd and orf $A$ coding regions, but containing the respective $5^{\prime}$ and $3^{\prime}$ flanking sequences, three primers were designed: R3 (5'-TCGCAACTAC ACCTATATGAGAGA), which was complimentary to nt 94-11 of the asd upstream sequence presented in Fig. 3 (the base complimentary to the A of the asd ATG initiation codon is underlined; R1 (5'TGATCGATCCGGCGCCGTCCGCAA), whose sequence was identical to nt $1230-1253$ and includes the asd stop codon (underlined); and R2 (5'-GTAAAAGATACTTACCCACAGATT), which is identical to nt 2342-2365 and includes the putative full-length orf $A$ stop codon (underlined). These primers were used to prime synthesis from pPS454 (Fig. 2; Table 1) DNA in a $50 \mu$ reaction mixture containing $1 \times T a q$ Plus buffer (Sangon) $(20 \mathrm{mM}$ Tris $/ \mathrm{HCl} \mathrm{pH} 8.8,10 \mathrm{mM} \mathrm{KCl}$, $10 \mathrm{mM}\left(\mathrm{NH}_{4}\right)_{2} \mathrm{SO}_{4}, 2 \mathrm{mM} \mathrm{MgSO}, \quad 0 \cdot 1 \%$ Triton X-100, $0 \cdot 1 \mathrm{mg} \mathrm{BSA} \mathrm{ml}), 200 \mu \mathrm{M}$ of each dNTP, $30 \mathrm{pmol}$ of each primer, $\sim 10$ pmol pPS454 DNA and $5 \mathrm{U}$ Taq Plus polymerase (Sangon). The reaction mixtures were subjected to the following cycles: 1 cycle at $97^{\circ} \mathrm{C}$ for $5 \mathrm{~min} ; 30$ cycles $\left(94^{\circ} \mathrm{C}\right.$, $\left.1 \mathrm{~min} ; 58^{\circ} \mathrm{C}, 45 \mathrm{~s} ; 72^{\circ} \mathrm{C}, 3.5 \mathrm{~min}\right)$; final extension at $72^{\circ} \mathrm{C}$ for 5 min. Combination of primers R 3 and $\mathrm{R} 2[\Delta($ asd-orf $A)]$ yielded a PCR product of $\sim 4.3 \mathrm{~kb}$ and combination of primers $\mathrm{R} 3$ and R1 ( $\Delta a s d$ ) yielded a PCR product of $\sim 5.2 \mathrm{~kb}$. The PCR fragments were treated $\left(20 \mathrm{~min}, 37^{\circ} \mathrm{C}\right)$ with T4 DNA polymerase in the presence of $100 \mu \mathrm{M}$ dNTPs, subjected to agarose gel electrophoresis and the fragments eluted utilizing the commercial Geneclean kit (Bio101). The fragments were then ligated either to the 1526 bp blunt-ended Gm-resistanceconferring EcoRI-HindIII fragment from pFGS1 (Table 1) or the $1714 \mathrm{bp}$ blunt-ended Gm-resistance-conferring Bam HI fragment from pPS716 (Table 1) to yield plasmids pPS730

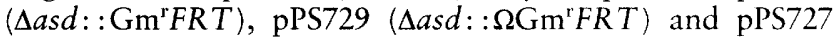
$\left[\Delta(\right.$ asd-orf $\left.A):: \Omega \mathrm{Gm}^{\mathrm{r}} F R T\right]$. The mutated regions were then subcloned as BamHI-NdeI fragments into pPS731 which contains the asd region cloned as a $6.5 \mathrm{~kb}$ blunt-ended EcoRI fragment into the Smal site of the gene replacement vector pEX100T (Schweizer \& Hoang, 1995). This procedure

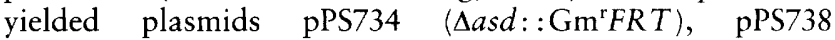
( $\left.\Delta a s d:: \Omega \mathrm{Gm}^{\mathrm{r}} F R T\right)$ and pPS735 [ $\Delta($ asd-orf $\left.A):: \Omega \mathrm{Gm}^{\mathrm{r}} F R T\right]$. For gene replacement, the previously described strategy was employed (Schweizer \& Hoang, 1995), except that $\mathrm{Gm}^{r}$ colonies were always selected, screened and maintained on VBMM-Gm media containing high concentrations $(1 \mathrm{mg}$ $\mathrm{ml}^{-1}$ ) DAP. Sucrose-resistant colonies were obtained and tested for DAP requirement and auxotrophies to methionine, threonine and lysine. The mutations in the strains PAO183

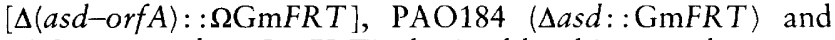
PAO185 ( $\triangle a s d:: \Omega G m F R T$ ) obtained by this procedure were verified by genomic Southern analyses (data not shown). 
SmaI

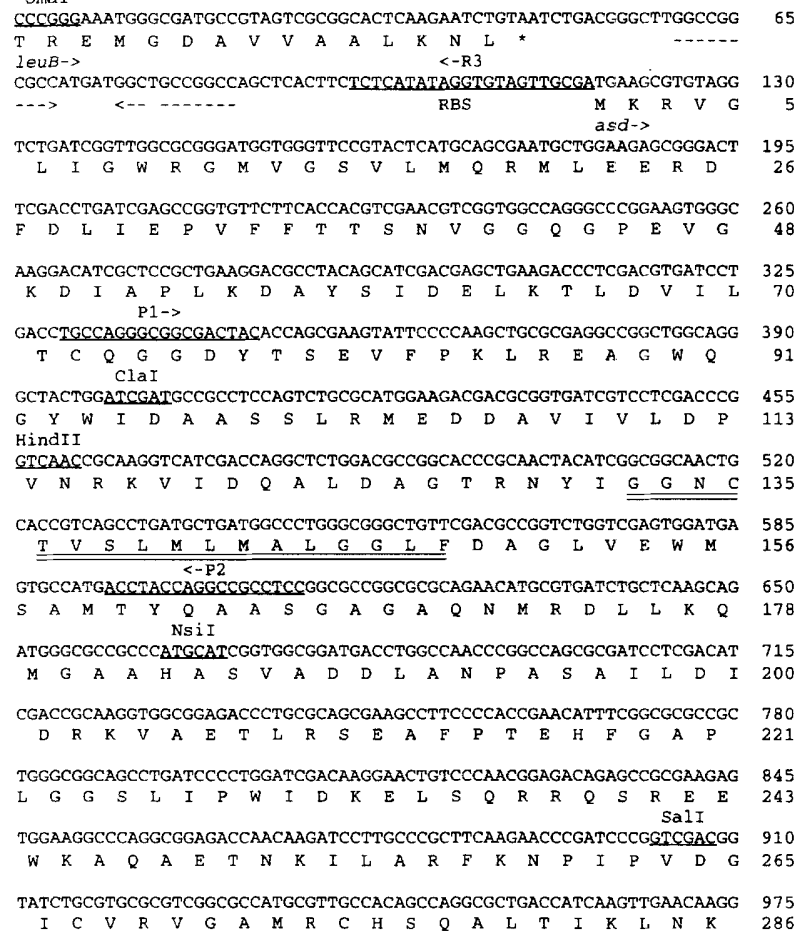

ATGTGCCGCTGACCGACATCGAGGGCCTGATCAGACAGCACAATCCCTGGGTCAAGCTGGTGCCG 1040

$\begin{array}{lllllllllllllllllllllll}D & V & P & L & T & D & I & E & G & L & I & R & Q & H & N & P & W & V & K & L & V & P & 308\end{array}$

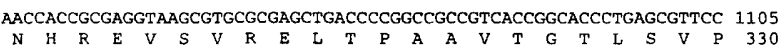

GGTCGGGCGCCTGCGCAAGTTGAACATGGTCTCCCAGTATCTCGGCGCCTTCACCGTCGGCGACC 1170

$\begin{array}{lllllllllllllllllllllll}V & G & R & L & R & K & \text { L } & N & M & V & S & Q & Y & \text { L } & G & A & F & T & V & G & D & 351\end{array}$ ClaI

AGTTGCTGTGGGGCGCTGCCGAGCCGCTGCGGCGCATGTTGCGCATCCTGCTGGAGCGCTGATCG 1235

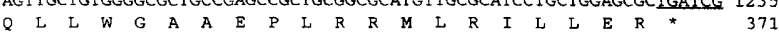
R1->

ATCCGGCGCCGTCCGCAATGGGCGGCGCCTCGATTGCCTGGGCGAAGGTGGGCAAGTAAAGTGCC 1300

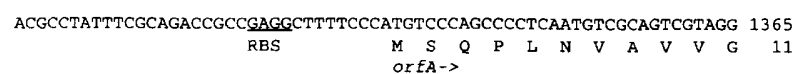
$\begin{array}{llllllllllll}\text { ACGCCTATTTCGCAGACCGCCGAGGCTTTTCCCATGTCCAGCCCTCAATGTCGATCGTAGG } & 1365 \\ \text { RBS } & \text { M S Q } & \text { P } & \text { L } & \text { N } & \text { V } & \text { A } & \text { V V V V } & \text { G } & 11\end{array}$ CGCCACCGGATCGGTTGGCGAGGCTCTGGTCGGTCTCCTCGACGAACGCGACTTCCCGCTTCATC 1430 $\begin{array}{llllllllllllllllllllll}A & T & G & S & V & G & E & A & L & V & G & L & L & D & E & R & D & F & P & L & H & 32\end{array}$ GTTTGCACCTGCTGGCCAGCGCCGAGTCGGCCGGGCAGCGCATGGGTTTCGCCGAAAGCAGCCTG 1495 $\begin{array}{lllllllllllllllllllllll}R & \text { L } & H & \text { L } & \text { L } & \text { A } & S & \text { A } & \text { E } & S & \text { A } & G & Q & \text { R } & \text { M } & G & \text { G } & \text { A } & \text { E } & \text { S } & S & \text { L } & 54\end{array}$ PUM $>$ SaCII
CGCGTCGGCGATGTCGATAGCTTCGATTTTTCCAGTGTCGGCCTGGCCTTCTTCGCCGCGGCAGC 1560 $\begin{array}{llllllllllllllllllllllllllllll}R & V & G & D & V & D & S & F & D & F & S & S & V & G & \text { L } & \text { A } & \text { F } & \text { F } & \text { A } & \text { A } & \text { A } & \text { A } & 76\end{array}$ CGAGGTGTCGCGTGCCCATGCCGAGCGCGCCCGCGCGGCGGGTTGTTCGGTGATCGACCTGAGCG 1625 $\begin{array}{llllllllllllllllllllll}\text { E } & \text { V } & \text { S } & \text { R } & \text { A } & \text { H } & \text { A } & \text { E } & \text { R } & \text { A } & \text { R } & \text { A } & \text { A } & G & \text { C } & \text { S } & \text { V } & \text { I } & \text { D } & \text { L } & \text { S } & \end{array}$ GCGCCCTGGAACCGAGCGTCGCACCGCCGGTCATGGTTTCGGTGAATOCCGAACGCCTGGCCTCG 1690 $\begin{array}{lllllllllllllllllllllllll}G & \text { A } & \text { L } & \text { E } & \text { P } & \text { S } & \text { V } & \text { A } & \text { P } & \text { P } & \text { V } & \text { M } & \text { V } & \text { S } & \text { V } & \text { N } & \text { A } & \text { E } & \text { R } & \text { L } & \text { A } & \text { S } & 119\end{array}$ CAAGCGGCGCCGTTCCTTATTGTCCAGTCCTTGCGCCGTAGCCGCCGAACTGTGCGAAGTGCTGG 1755

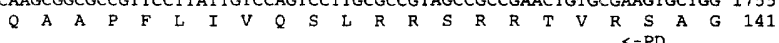
CGCCACTCCTGGCCACGCTGGATTGCCGGCAACTGAACCTGACAGCCTGCCTCTCCGTCTCCAGC 1820

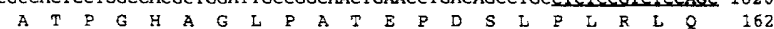
CTGGGGCGCGAAGGGGTCAAGGAACTCGCCCGGCAGACCGCCGAACTGCTCAATGCGCGCCCCCT 1885 $\begin{array}{lllllllllllllllllllllllll}P & G & A & R & R & G & Q & G & T & R & P & A & D & R & R & T & A & Q & C & A & P & P & 184\end{array}$ GGAGCCGCGTCTCTTCGACCGCCAGATCGCCTTCAACCTGCTCGCGCAGGTCGGAGCGGTGGATG 1950 $\begin{array}{lllllllllllllllllllllllll}G & \text { A } & \text { A } & S & \text { L } & \text { R } & \text { P } & \text { P } & \text { D } & R & \text { L } & Q & \text { P } & \text { A } & R & \text { A } & G & \text { R } & \text { S } & G & G & C & 206\end{array}$ $\begin{array}{lllllllllllllllllll}G & A & A & S & L & R & P & P & D & R & L & Q & P & A & R & A & G & R & S\end{array}$ $\begin{array}{lllllllllllllllllllllll}R & G & T & Q & R & D & R & A & A & H & \text { L } & R & G & G & A & G & \text { L } & \text { A } & \text { W } & R & \text { A } & 227\end{array}$

ATCGGACCGTTGAACGTTACETGCATCCAGGCGCCGGTATTCTTCGGCGATAGCCTCAGCGTGAC 2080

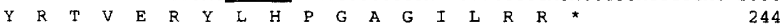

CCTGCAGTGCGCGGAACCGGTGGACCTGGCCGCGGTGACGCGGGTCCTCGATGCGACGAAAGGTA 2145

TCGAATGGGTCGGCGAGGGCGATTATCCGACGGTGGTCGGCGATGCCCTCGGCCAGGACGAGACC 2210

TATGTCGGCCGGGTGAGGGCGGGGCAGGCTGATCCCTGTCAGGTCAATTTGTGGATTGTGTCTGA 2275 TAATGTGCGAAAAGGTGCCGCGCTGAATGCCGTGCTCCTGGGTGAGTTGTTGATAAAACACTATC 2340 R2-> * Stop NsiI

\section{RESULTS AND DISCUSSION}

\section{Cloning of the asd gene of $P$. aeruginosa}

The partial asd coding sequence was successfully amplified from $P$. aeruginosa chromosomal DNA by employing two oligonucleotide primers (P1 and P2; marked in Fig. 3) with minor degeneracy modelled after conserved amino acid sequence regions found in all Gram-negative Asd proteins cloned and sequenced to date. Under the experimental conditions employed in this study, amplification was very specific and the $281 \mathrm{bp}$ amplified DNA fragment comprised $>99 \%$ of the observed PCR products (data not shown). With the help of the PCR-generated, cloned DNA fragment, the entire asd gene was cloned utilizing the strategy described in Methods. The physical maps of some representative asd clones are shown in Fig. 2. Plasmid pPS412 DNA when used to transform $\Delta a s d$ strain $\mathrm{SH} 309$ was able to complement the asd mutation of this strain. Deletion of a $1.4 \mathrm{~kb} \mathrm{SmaI}$ fragment (pPS455) or $1.2 \mathrm{~kb} \mathrm{BamHI-PstI}$ fragment (achieved by subcloning of the SmaI-Pst I fragment from pPS455 to form pPS456) had no effect on asd complementing activity, localizing the asd gene between the Pst I and SmaI sites. Finally, partial digestion with ClaI and subcloning of a $1.2 \mathrm{~kb}$ ClaI-SmaI fragment into pBluescript SK localized asd between these sites on pPS457. This location was verified by deletion of the $0.8 \mathrm{~kb} \mathrm{Clal}$ fragment and replacement with a $\mathrm{Gm}^{\mathrm{r}}$ marker (pPS452). The resulting pPS452 could no longer complement the asd deletion of SH309.

\section{Sequence analysis of the asd gene region}

To verify that the cloned gene fragment contained asd, the nucleotide sequence of a 2433 bp SmaI-Nsil fragment was determined (Fig. 3). The sequence defines three ORFs extending from nt 1 to 44 , nt 117 to 1229 and nt 1334 to 2065 , which are separated by short intergenic regions. Although both of these contain palindromic sequences that could possibly serve as Rho-independent transcription termination signals (Rosenberg \& Court, 1979), no promoter sequences are readily apparent.

Fig. 3. Nucleotide sequence of the cloned $P$. aeruginosa asd region. The nucleotide sequence of a Nsil-Smal fragment (Fig. 2) is shown. PCR-amplified chromosomal sequences (nt 330-608) are marked by the inverted arrows above the sequence. The predicted amino acid sequences of the asd, leuB and orf $A$ reading frames are indicated below the appropriate codons. The putative ribosome binding sites (RBS) are marked. The amino acid residues constituting part of the Asd active site are double-underlined. Sequences located in the leuB-asd and asd-orfA intergenic regions that may serve as Rho-independent transcriptional terminators for leuB $\left[\Delta G=-31.7 \mathrm{kcal} \mathrm{mol}^{-1}\right.$ $\left.\left(-132.6 \mathrm{~kJ} \mathrm{~mol}^{-1}\right)\right]$ or asd $\left[\Delta G=-27.5 \mathrm{kcal} \mathrm{mol}^{-1}(-115.06 \mathrm{~kJ}\right.$ $\left.\left.\mathrm{mol}^{-1}\right)\right]$, respectively, are underlined with the inverted arrows. The location of priming sites for PCR primers mentioned in the text are underlined and the $5^{\prime}$ to $3^{\prime}$ direction of synthesis from these primers is indicated by the arrow next to the primer label. A vertical slash labelled 1673 marks the location of nucleotide G1673 that was arbitrarily deleted to extend OrfA to the indicated stop codon (nt 2343-2345) and to achieve the alignments to Vibrio spp. Asd proteins are discussed in the text. 


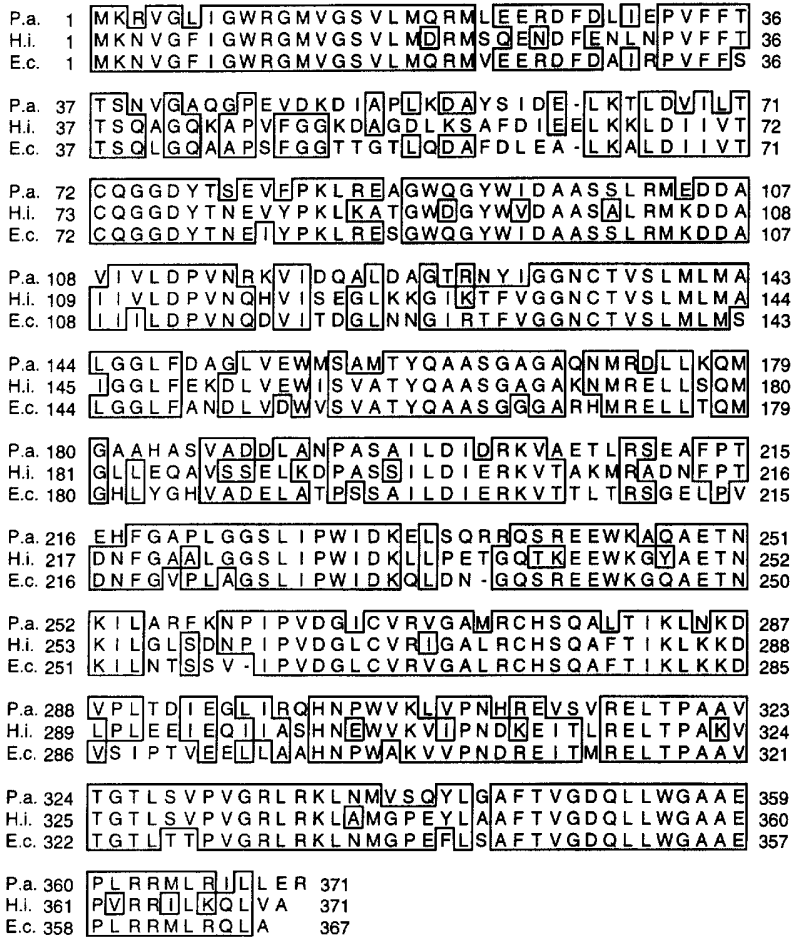

Fig. 4. Amino acid sequence alignment generated utilizing the SeqVu program (Garvan Medical Institute, Sidney, Australia). Alignments of Asd of $P$. aeruginosa (P.a.) with Asd from $H$. influenzae (H.i.) (GenBank accession number L42023) and $E$. coli (E.C.) (GenBank accession number V00262) are shown. The similarities of the Asd proteins are $82 \%$ (P.a. vs H.i.) and $77 \%$ (P.a. vs E.C.).

However, in the absence of transcriptional analyses no definitive conclusions about the transcriptional arrangements of the genes encoding these ORFs can be drawn.

The shortest ORF extends from nt 1 to 44 and was previously shown to constitute the C-terminal part of the $P$. aeruginosa LeuB homologue (Hoang \& Schweizer, 1997).

The longest ORF is encoded by nt $117-1229$ and encodes 371 residues with a combined molecular mass of 40917. BLAST and PROSITE searches revealed that this protein shares significant identity to other Asd proteins (Fig. 4). Alignments of the predicted amino acid sequence of Asd from $P$. aeruginosa with the corresponding sequences from E. coli and Haemophilus influenzae revealed greater than $80 \%$ similarity and for long stretches the sequences align perfectly. In contrast, when compared to the Asd proteins from Bacillus subtilis (GenBank accession number Z22554), Streptococcus mutans (Cardineau \& Curtiss, 1987) and Vibrio cholerae (GenBank accession number X55363), much less similarity exists between the deduced amino acid sequences of either Asd proteins (data not shown). While it is not surprising that the Asd sequences from Gram-negative bacteria are more conserved amongst each other as compared to Gram-positive bacteria, it is surprising that
Asd from V. cholerae shows little homology to Gramnegative sequences but higher homology to Grampositive sequences.

A second ORF extends from nt 1334 to 2065 and encodes 244 amino acid residues specifying a polypeptide with a calculated molecular mass of 25543. BLAST analyses indicated that the first 114 residues of this protein had significant similarity to the Grampositive-like Asd proteins, especially the Asd proteins from several Vibrio species. Since this homology did not extend beyond residue 114 and since a closer inspection of the residual OrfA coding sequence revealed a codon usage somewhat atypical of $P$. aeruginosa (West $\&$ Iglewski, 1988), we considered the possibility of a frameshift mutation contained on the cloned and sequenced DNA fragments. This notion was further supported by the fact that arbitrary deletion of a single $\mathrm{G}$ residue at position 1673 (Fig. 3) allowed translation of the same ORF to a TAA stop codon at nt 2343-2345. This ORF would contain at least 336 amino acid residues with a calculated molecular mass of 35611 . Thus, it would be very similar in size and amino acid composition to the Asd proteins from selected Vibrio species.

To rule out the possibility of a frameshift mutation contained on the cloned and sequenced DNA fragments, two primers (PU and PD; Fig. 3) were designed, and the intervening region was PCR-amplified from genomic PAO1 DNA and sequenced. The sequence thus obtained was identical to the one determined from the cloned DNA segments. Furthermore, PCR amplification and nucleotide sequence analysis of the same region from genomic DNA of another unrelated $P$. aeruginosa strain, UO606, which is a $g l p K:: \operatorname{Tn} 5 \mathrm{Gm}$ derivative of the prototrophic strain PG201 (Ochsner et al., 1994), yielded an identical sequence. Therefore, it is most likely that the orf $A$ region from the analysed $P$. aeruginosa strains is naturally frame-shifted and therefore does not express a protein with Asd function. This notion is further supported by several other observations: (i) non-polar and polar $\mathrm{Gm}^{\mathrm{r}}$ insertions in chromosomal asd confer the same Asd $^{-}$phenotype; (ii) pPS457 and a similar broadhost-range derivative containing only the asd coding region complements the Asd phenotype of $P$. aeruginosa $\Delta($ asd-orf $A)$ and $\Delta a s d$ mutants, as well as E. coli $\Delta a s d$ (Fig. 2); and (iii) plasmids containing the cloned asd region in E. coli highly express LeuB and Asd from the lac promoter but neither a $26 \mathrm{kDa}$ nor a $36 \mathrm{kDa}$ protein (Hoang \& Schweizer, 1997). Thus, the biological significance of orfA and its product, if any, remain unknown.

\section{Conserved sequences of Gram-negative Asd proteins containing the active site residues}

In conjunction with earlier ligand experiments, Biellmann et al. (1980) and Haziza et al. (1982) identified the sequence FVGGNCTVS as being part of the active site residues of Asd from E. coli. When an extended version of this sequence was used in a BLASTP search of 
GenBank, similar sequences with the consensus GGNCTVXMLMXXXLGLF (double-underlined in Fig. 3) differing by only a few conserved substitutions were found in almost identical positions in the Asd proteins from all of the Gram-negative bacteria from which the sequences are available to date. Although these amino acid sequences are thought to comprise part of the active site residues, they were not readily apparent in Asd from Vibrio species and the Gram-positive bacteria. Thus, the above consesus sequence may be used as a signature motif for Gram-negative Asd proteins.

\section{Identification of the asd gene product}

To identify the Asd polypeptide, the $P$. aeruginosa wildtype asd gene was expressed in the T7 RNA polymerase/T7 promoter expression system (Studier $e t$ al., 1990). Only pT7-5asd containing asd in the same orientation as the T7 promoter highly expressed an IPTG-inducible single protein with an estimated molecular mass of $40 \mathrm{kDa}$ (data not shown). This polypeptide was not expressed from pT7-6asd carrying asd in the opposite orientation and was also absent from vector-containing cells. The observed size $(40 \mathrm{kDa})$ of the $P$. aeruginosa Asd polypeptide compares very favourably with the size deduced from the nucleotide sequence (40917), as well as the predicted sizes of 40015 for the E. coli (GenBank accession number V00262) and 40537 for the $H$. influenzae (GenBank accession number L42023) Asd proteins.

\section{Isolation of a chromosomal asd mutation}

As detailed in Methods, several chromosomal $\Delta a s d$ mutations were isolated either by replacing the asd gene alone or by replacing the asd-orf $A$ encoding sequences with different $\mathrm{Gm}$-resistance-conferring cassettes. Selection of these cassettes allowed isolation of the following mutants: PAO183 $\left[\Delta(\right.$ asd-orfA $\left.):: \Omega \mathrm{Gm}^{\mathrm{r}} F R T\right]$, PAO184 ( $\triangle$ asd: : $\mathrm{Gm}^{\mathrm{r}} F R T$ ) and PAO185 ( $\triangle$ asd: : $\left.\Omega \mathrm{Gm}^{\mathrm{r}} F R T\right)$. On VBMM minimal medium, all of these mutants were auxotrophic for DAP, lysine, methionine and threonine but grew on this medium in the presence of DAP. This indicated that the biosynthetic pathways for these amino acids (Fig. 1) are probably similar to those proposed for E. coli and S. typhimurium (Patte, 1996; Greene, 1996), with the exception of the pathway from homoserine to methionine which was shown to be different in $P$. aeruginosa (Foglino et al., 1995). The mutant required high $\left(1 \mathrm{mg} \mathrm{ml}^{-1}\right)$ concentrations of DAP, and even at these levels its growth rate was slower than the one observed with its parent, PAO1. This is probably due to the fact that $P$. aeruginosa does not effectively transport DAP (Martin et al., 1986), a notion which is further corroborated by the finding that even in the presence of DAP, the mutant did not grow as well on minimal medium lacking lysine as did wild-type PAO1. In the absence of DAP, the mutants lysed rapidly. All mutants were complemented by pPS600 containing the asd gene cloned in the broad-host-range vector pUCP20T (Schweizer et al., 1996).

\section{Chromosomal mapping of the cloned asd gene}

The asd gene was located on the PAO1 chromosome by hybridization of labelled pPS410 to Southern blots of $D p n \mathrm{I}-$ and SpeI-digested genomic DNA, which previously had been separated by PFGE (Lightfoot $\&$ Lam, 1993) (data not shown). In blots of SpeI-digested chromosomal DNA, the asd sequences hybridized to a restriction fragment of approximately $260 \mathrm{~kb}$, corresponding to restriction fragment SpeI-I (Holloway et al., 1994). Similarly, the same probe hybridized to a $D p n \mathrm{I}$ fragment of approximately $580 \mathrm{~kb}$, which corresponds to fragment $D p n I-\mathrm{D}$. Thus, the asd gene was mapped to between 1.85 and $2.15 \mathrm{Mbp}$ on the $5.9 \mathrm{Mbp}$ chromosome, which corresponds to the $37-40 \mathrm{~min}$ region of the genetic map (Holloway et al., 1994). The results demonstrate that $P$. aeruginosa contains a single copy of the asd gene. Interestingly, the asd gene, whose function is required for lysine, methionine and threonine biosynthesis, maps to the same macrorestriction fragments as some other genes involved in amino acid biosynthesis and/or metabolism, for example leu-10, trpF, met-9011 and oru-314 (Holloway et al., 1994), and we have recently shown that $l e u-10$ is allelic with $l e u B$, encoding 3-isopropylmalate dehydrogenase (Hoang \& Schweizer, 1997).

\section{Conclusions}

The results described in this paper demonstrate that the asd gene encoding aspartate- $\beta$-semialdehyde dehydrogenase from $P$. aeruginosa was successfully cloned and expressed. Although the asd downstream region contains a putative gene, orf $A$, whose product showed significant homology to the Gram-positive-like Asd proteins from Vibrio spp., molecular and genetic analyses indicated that $\operatorname{orf} A$ is naturally frame-shifted in all $P$. aeruginosa strains tested so far. Thus, its physiological role, if any, in DAP biosynthesis remains to be elucidated. Chromosomal mapping studies and mutational analyses indicated that $P$. aeruginosa contains a single copy of asd. However, this does not rule out the existence of a second (silent) gene encoding an Asd-like activity elsewhere in the chromosome, which may be revealed by reversion analysis of the asd insertion mutants described in this study. The anticipated role of asd in the biosynthetic pathways of DAP, lysine, methionine and threonine (Fig. 1) was supported by mutational analyses. The studies also indicated that asd is not closely linked to any of the hitherto unidentified aspartokinase (ask) gene(s).

It is anticipated that the availability of the cloned gene will facilitate future genetic studies of this organism based on exploitation of the essential nature of asd. Since asd mutants have an obligate requirement for $\mathrm{DAP}$, in the laboratory they will only grow on media supplemented with DAP, or after acquiring the asd gene 
on a complementing DNA fragment. The latter can be exploited for in vivo maintenance of recombinant plasmids containing an 'asd cassette' as the selectable marker in a genetically engineered asd deletion background. In addition, it is anticipated that this will provide a powerful means for isolation and selection of defined chromosomal insertion and deletion mutants. Given the problems with using antibiotic resistance markers in this bacterium, such a 'metabolic' genetic element based on an essential bacterial gene presents an attractive alternative method for gene manipulation and analysis. Finally, one could imagine as $d$ as an alternative selectable marker for the emerging in vivo expression technology (IVET) strategies (Slauch et al., 1994; Wang et al., 1996). Given that, in contrast to some of the other selectable markers present on currently available constructs, it is 'bacteria-specific', asd may offer a better alternative. To facilitate such studies our laboratory has already (i) isolated a defined $\Delta($ asd-orf $A) P$. aeruginosa host strain devoid of any antibiotic resistance marker by employing Flp-recombinase-mediated excision (Cherepanov \& Wackernagel, 1995) of the $\Omega \mathrm{Gm}^{\mathrm{r}} F R T$ cassette contained in strain PAO183 $\Delta($ asd-orf $A):: \Omega \mathrm{Gm}^{\mathrm{r}} F R T$ and (ii) genetically engineered a defined asd cassette for use in vector construction.

\section{ACKNOWLEDGEMENTS}

S.W. was supported by a Summer Studentship from the Alberta Heritage Foundation for Medical Research. Financial support to H.P.S. was provided by a Medical Scholarship of the Medical Research Council (MRC) of Canada, MRC operating grant MT-11245, by funds from the Canadian Bacterial Diseases Network, and by start-up funds from Colorado State University.

\section{REFERENCES}

Biellmann, J. P., Eid, P., Hirth, C. \& Joernvall, H. (1980). Aspartate$\beta$-semialdehyde dehydrogenase from Escherichia coli. Affinity labeling with the substrate analogue L-2-amino-4-oxo-5-chloropentanoic acid: an example of half-site reactivity. Eur J Biochem 104, 59-64.

Bodey, G. P., Bolivar, R., Fainstein, V. \& Jadeja, L. (1983). Infections caused by Pseudomonas aeruginosa. Rev Infect Dis 5, 279-313.

Cardineau, G. A. \& Curtiss, R. (1987). Nucleotide sequence of the asd gene of Streptococcus mutans. J Biol Chem 262, 3344-3353.

Chamberlain, J. P. (1979). Fluorographic detection of radioactivity in polyacrylamide gels with the water-soluble fluor, sodium salicylate. Anal Biochem 98, 132-135.

Cherepanov, P. P. \& Wackernagel, W. (1995). Gene disruption in Escherichia coli: $\mathrm{Tc}^{\mathrm{R}}$ and $\mathrm{Km}^{\mathrm{R}}$ cassettes with the option of Flpcatalyzed excision of the antibiotic-resistance determinant. Gene $158,9-14$.

Clepet, C., Borne, F., Krishnapillai, V., Baird, C., Patte, J. C. \& Cami, B. (1992). Isolation, organization and expression of the Pseudomonas aeruginosa threonine genes. Mol Microbiol 6, 3109-3119.

Cryz, S. J., Jr, Pitt, T. L., Furer, E. \& Germaier, R. (1984). Role of lipopolysaccharide in virulence of Pseudomonas aeruginosa. Infect Immun 44, 508-513.
Foglino, M., Borne, F., Bally, M., Ball, G. \& Patte, J. C. (1995). A direct sulfhydrylation pathway is used for methionine biosynthesis in Pseudomonas aeruginosa. Microbiology 141, 431-439.

Govan, J. R. W. (1988). Alginate biosynthesis and other unusual characteristics associated with the pathogenesis of Pseudomonas aeruginosa in cystic fibrosis. In Bacterial Infections of Respiratory and Gastrointestinal Mucosa, pp. 67-96. Edited by W. Donachie, E. Griffiths \& J. Stephen. Oxford: IRL Press.

Greene, R. C. (1996). Biosynthesis of methionine. In Escherichia coli and Salmonella, pp. 542-560. Edited by F. C. Neidhardt, R. Curtiss, III, J. L. Ingraham and others. Washington, DC: American Society for Microbiology.

Haziza, C., Stragier, P. \& Patte, J.-C. (1982). Nucleotide sequence of the asd gene of Escherichia coli: absence of a typical attenuation signal. EMBO J 1, 379-384.

Hoang, T. T. \& Schweizer, H. P. (1997). Leucine biosynthesis in Pseudomonas aeruginosa: identification and characterization of leuB, encoding 3-isopropylmalate dehydrogenase. Mol Gen Genet (in press).

Hoiby, N., Pedersen, S. S., Shand, G. H., Doering, G. \& Holder, I. A. (1989). Pseudomonas aeruginosa infection. Antibiot Chemother 42, 1-300.

Holder, I. A. \& Neely, A. N. (1991). The role of proteases in Pseudomonas infections in burns: a current hypothesis. Antibiot Chemother 44, 99-105.

Holloway, B. W. \& Zhang, C. (1990). Genetic maps. In Locus Maps of Complex Genomes, pp. 2.71-2.78. Edited by S. J. O'Brien. Cold Spring Harbor, NY: Cold Spring Harbor Laboratory.

Holloway, B. W., Römling, U. \& Túmmler, B. (1994). Genomic mapping of Pseudomonas aeruginosa PAO. Microbiology 140, 2907-2929.

Kureishi, A. \& Bryan, L. E. (1992). Pre-boiling high GC content, mixed primers with $3^{\prime}$ complementation allows the successful PCR amplification of Pseudomonas aeruginosa DNA. Nucleic Acids Res 20, 1155.

Lightfoot, J. \& Lam, J. S. (1993). Chromosomal mapping, expression and synthesis of lipopolysaccharide in Pseudomonas aeruginosa: a role for guanosine diphospho (GDP)-D-mannose. Mol Microbiol 8, 771-782.

Liss, L. (1987). New M13 host: DH5 $\alpha \mathrm{F}^{\prime}$ competent cells. Focus 9 , 13.

Makowski, G. S. \& Ramsby, M. L. (1993). $\mathrm{pH}$ modification to enhance the molecular sieving properties of sodium dodecyl sulfate-10\% polyacrylamide gel. Anal Biochem 212, 283-285.

Martin, C., Cami, B., Jeenes, D. D., Haas, D. \& Patte, J.-C. (1986). Heterologous expression and regulation of the lys $A$ gene of Pseudomonas aeruginosa and Escherichia coli. Mol Gen Genet 203, 430-434.

Miller, J. H. (1992). A Short Course in Bacterial Genetics. Cold Spring Harbor, NY: Cold Spring Harbor Laboratory.

Nakayama, K., Kelly, S. M. \& Curtiss, R. (1988). Construction of an $\mathrm{Asd}^{+}$expression-cloning vector: stable maintenance and high level expression of cloned genes in a Salmonella vaccine strain. BioTechnology 6, 693-697.

Ochsner, U. A., Koch, A. K., Fiechter, A. \& Reiser, J. (1994). Isolation and characterization of a regulatory gene affecting rhamnolipid synthesis in Pseudomonas aeruginosa. J Bacteriol 176, 2044-2054.

Patte, J.-C. (1996). Biosynthesis of threonine and lysine. In Escherichia coli and Salmonella, pp. 528-541. Edited by F. C. 
Neidhardt, R. Curtiss, III, J. L. Ingraham and others. Washington, DC: American Society for Microbiology.

Rosenberg, M. C. \& Court, D. (1979). Regulatory sequences involved in the promotion and termination of RNA transcription. Annu Rev Genet 13, 319-353.

Sambrook, J., Fritsch, E. F. \& Maniatis, T. (1989). Molecular Cloning: a Laboratory Manual, 2nd edn. Cold Spring Harbor, NY : Cold Spring Harbor Laboratory.

Schleifer, K. H. \& Kandler, O. (1972). Peptidoglycan types of bacterial cell walls and their taxonomic implications. Bacteriol Rev 36, 407-477.

Schweizer, H. P. (1991). The agmR gene, an environmentally responsive gene, complements defective $g l p R$, which encodes the putative activator for glycerol metabolism in Pseudomonas aeruginosa. J Bacteriol 173, 6798-6806.

Schweizer, H. P. \& Hoang, T. (1995). An improved system for gene replacement and $x y l E$ fusion analysis in Pseudomonas aeruginosa. Gene 158, 15-22.

Schweizer, H. P. \& Po, C. (1994). Cloning and nucleotide sequence of the $g l p D$ gene encoding $s n$-glycerol-3-phosphate dehydrogenase from Pseudomonas aeruginosa. J Bacteriol 176, 2184-2193.

Schweizer, H., Sweet, G. \& Larson, T. J. (1986). Physical and genetic structure of the $g l p D-$ malT interval of the Escherichia coli K-12 chromosome. Mol Gen Genet 202, 488-492.

Schweizer, H. P., Klassen, T. R. \& Hoang, T. (1996). Improved methods for gene analysis and expression in Pseudomonas. In Molecular Biology of Pseudomonads, pp. 229-237. Edited by T. Nakazawa, K. Furukawa, D. Haas \& S. Silver. Washington, DC: American Society for Microbiology.

Slauch, J. M., Mahan, M. J. \& Mekalanos, J. J. (1994). In vivo expression technology for selection of genes specifically induced in host tissues. Methods Enzymol 235, 481-492.

Studier, F. W., Rosenberg, A. H., Dunn, J. J. \& Dubendorff, J. W.
(1990). Use of T7 RNA polymerase to direct expression of cloned genes. Methods Enzymol 185, 60-89.

Tabor, S. (1994). Expression using the T7 RNA polymerase/ promoter system. In Short Protocols in Molecular Biology, pp. 16.1-16.10. Edited by F. M. Ausubel, R. Brent, R. E. Kingston and others. New York: John Wiley.

Vasil, M. L. (1986). Pseudomonas aeruginosa: biology, mechanisms of virulence, epidemiology. J Pediatr 108, 800-805.

Vasil, M. L., Graham, M. L., Ostroff, R. M., Shortridge, V. D. \& Vasil, A. I. (1991). Phospholipase C: molecular biology and contribution to the pathogenesis of Pseudomonas aeruginosa. Antibiot Chemother 44, $34-47$.

Wang, J., Mushegian, A., Lory, S. \& Jin, S. (1996). Large-scale isolation of candidate virulence genes of Pseudomonas aeruginosa by in vivo selection. Proc Natl Acad Sci USA 93, 10434-10439

West, S. E. H. \& Iglewski, B. H. (1988). Codon usage in Pseudomonas aeruginosa. Nucleic Acids Res 16, 9323.

West, S. E. H., Schweizer, H. P., Dall, C., Sample, A. K. \& RunyenJanecky, L. J. (1994). Construction of improved EscherichiaPseudomonas shuttle vectors derived from pUC18/19 and the sequence of the region required for their replication in Pseudomonas aeruginosa. Gene 128, 81-86.

Wieslander, L. (1979). A simple method to recover intact high molecular weight RNA and DNA after electrophoretic separation in low gelling temperature agarose gels. Anal Biochem 98, 305-309.

Xiang, C., Wang, H., Shiel, P., Berger, P. \& Guerra, D. J. (1994). A modified alkaline lysis miniprep protocol using a single microcentrifuge tube. BioTechniques 17, 30-31.

Yanisch-Perron, C., Vieira, J. \& Messing, J. (1985). Improved M13 cloning vectors and host strains: nucleotide sequences of the M13mp18 and pUC19 vectors. Gene 33, 103-119.

Received 12 July 1996; revised 16 September 1996; accepted 4 October 1996. 